\title{
INFLATION TARGETING: TO FORECAST OR TO SIMULATE?
}

\author{
Michal Skořepa*, Viktor Kotlán**
}

\begin{abstract}
:
Perhaps the most notable development in the area of monetary policy over the last decade is the growing popularity of inflation targeting. This regime is based to a great extent on communication and, more specifically, on using and communicating assessments of future inflation. The central banking literature, however, devotes surprisingly little attention to some important issues connected with such assessments. There are some non-trivial choices that need to be made regarding future inflation assessments on three distinct levels: construction, decision making and communication. One of the most important choices relates to the treatment of central bank's behaviour within the assessment. We differentiate between forecast and simulation as two basic ways of assessing future inflation and we discuss the pros and cons of using the two ways of assessing future inflation on the three above-mentioned levels.
\end{abstract}

Keywords: monetary policy, inflation targeting, forecast, simulation, projection, communication, decision making

JEL Classification: E52, E58

\section{Introduction and Basic Terms}

Inflation targeting relies heavily on an assessment of the future path of inflation. In view of this fact, relatively little discussion has been devoted in the literature to the

\footnotetext{
*) Czech National Bank, Na Př́íkopě 28, CZ - 115 03, Prague 1, and Institute of Economic Studies, Faculty of Social Sciences, Charles University, Opletalova 26, CZ - 110 00, Prague 1

(m.sko@seznam.cz)

**) Česká spořitelna, a.s., Na Perštýně 1, CZ - 11398 Prague 1, and VŠB - Technical University, Sokolská 33, CZ - 12001 Ostrava 1

*** ) This is a somewhat revised version of Skořepa \& Kotlán (2003). Our thanks for useful comments go to Nicoletta Batini, Jaromír Beneš, Aleš Čapek, Oldřich Dědek, Aaron Drew, Mojmír Hampl, Tomáš Holub, Douglas Laxton, Kateřina Šmídková and participants at the Workshop on Macroeconomic Policy Research at the National Bank of Hungary and at the Autumn Central Bank Economists' Meeting at the Bank for International Settlements, both held in October 2002. The views expressed are those of the authors, and not necessarily those of the Czech National Bank or Česká spořitelna, a.s.
} 
numerous non-trivial questions that arise in connection with the assessment of future inflation on three distinct levels: the construction of such an assessment, its use in monetary policy decision-making and its communication to the public. The present paper aims to fill this gap.

From many aspects of the assessment of the future, we focus on the treatment of the behaviour of the central bank, because this is the aspect that is most intimately connected with actual monetary policy decision-making. Before discussing the pros and cons of the alternative treatments, we need to say a few words on terminology. Usually, when assessing the future, one tries to draw its most likely picture i.e. to use the most likely scenario of each exogenous variable, at each time period to select the most likely reaction of each economic agent represented in the model, while taking the most likely value of each coefficient, etc. The most likely picture of the future is often called a forecast, but we encounter other labels too, such as prediction, outlook, projection, etc. ${ }^{1)}$ In central-banking circles, this way of looking into the future is often referred to as an "unconditional forecast" to distinguish it from a "conditional forecast", which is a purposeful attempt to draw not simply the most likely picture of the future, but the most likely picture of the future if the central bank does not change the level of its interest rate throughout the forecasted period. An assessment of the future in which a given agent is "forced" to behave in a specific (not necessarily the most likely) way is often called a simulation or a (policy) experiment. This terminology is illustrated in Figure 1.

Figure 1

\section{Basic Types of Assessments of the Future Behaviour of the Central Bank}

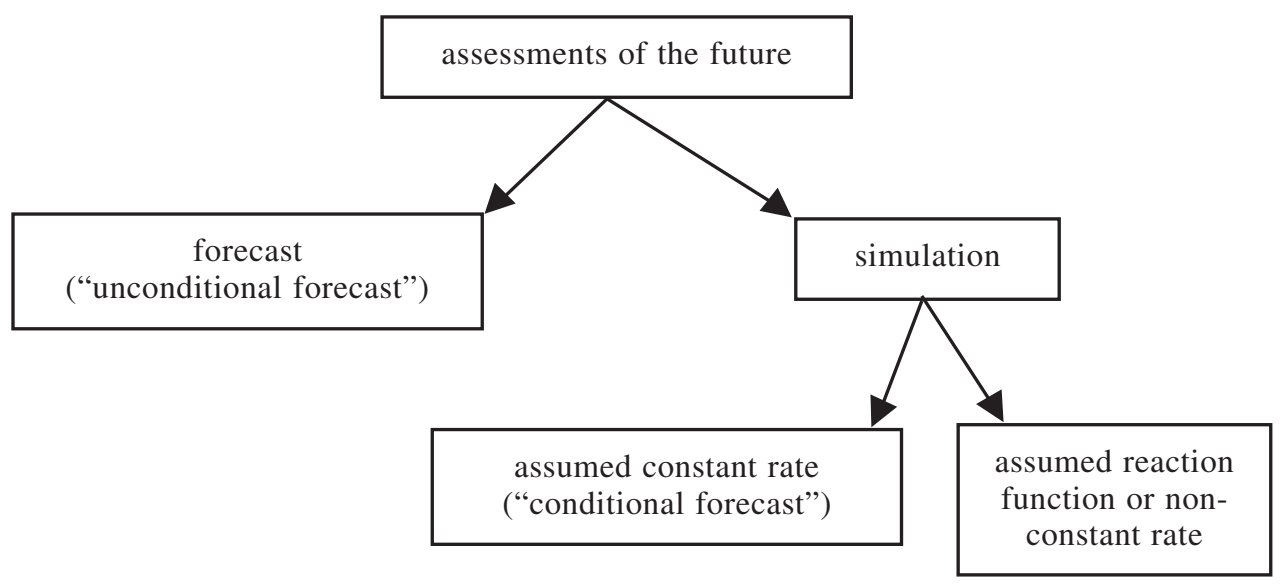

1) Given that we focus in this whole study on the central-banking environment, we take it for granted that the assessment of the future, whatever type of assessment it is, is constructed using objective, up-to-date forecasting technologies. It should also be noted that the words "most likely" are used here in a general sense of expected value or median or mode. 
The labels "conditional" and "unconditional" are potentially misleading, because in reality every assessment of the future is conditional on some assumptions, whereas the above use of the terms restricts the terminology to just one special type of conditionality. That is why we believe that the intuitive terminology "forecasts" versus "simulations" is preferable.

In practice, when building a model on which to base a forecast, the reactions of the central bank are usually generated by a reaction function. This is a specific equation in which the value of the decision variable (typically the central bank's interest rate) is determined by the past, current or expected values of various variables in a way that - at least in the opinion of the model-builders - approximates the decision-making criteria of the central bank's actual decision-makers (from now on referred to as "the Board"). The approximation, of course, has to be chosen with regard to the tractability of the resulting model. In simulations, the trajectory of the Board's decisions may be determined directly by the model-builder without any modelling, or it may be generated by inserting various (not necessarily the most likely) reaction functions into the predictive model. ${ }^{2}$

Clearly enough, there is usually just one forecast at each point in time (except in cases like multiple equilibria) because just one picture of the future is usually the most likely one. On the other hand, there can be as many simulations as we can devise trajectories of the central bank's future decisions.

At first glance, it may seem straightforward that obtaining and using a standard forecast, i.e. the most likely picture of the future, is preferable and that it makes little sense to weaken the predictive value of the forecast by making it a simulation, i.e. by assuming that one of the agents will behave in a way that is not necessarily the most likely one (so that the overall result may not be the most likely assessment of the future). In fact, however, only very few central banks (those in New Zealand, the Czech Republic and Norway) have opted for the forecast option, while most other inflation targeting central banks have been more in favour of simulations: they are used by central banks in Australia, Hungary, Poland and Switzerland, to name just a few examples. The primary reason seems to be the fact that simulations make it possible to "evaluate" - as Lucas (1976) puts it - alternative policies.

The goal of the present paper is to identify the advantages and disadvantages of using forecasts and simulations in the areas of their construction, their use in monetary policy decision-making and their communication. The rest of the paper is organised accordingly: Sections 2 to 4 compare the two types of looking into the future on these three levels, and Section 5 concludes.

\section{Construction of Simulations and Forecasts}

To avoid any misunderstanding, we emphasise that since the most common difference between forecasts and simulations as used in central banking practice is their treatment of the central bank, the comparison in this and the following sections will

2) Note that we consider the short-term interest rate to be the central bank's only instrument and think of the exchange rate as being determined within the model. If FX interventions were to be considered as a standard policy instrument, the discussion of simulations would have to be enriched accordingly. 
be based on this difference alone. Problems that are common to both forecasts and simulations will be suppressed. In this section we want to compare simulations and forecasts in terms of their construction.

\subsection{Simulations and the Lucas Critique}

In reality, all agents quite naturally expect that all other agents will behave in the future in the most likely way. If one of the agents, namely the central bank, then in fact behaves (as the simulation generally assumes) in a way that was not judged the most likely, this will surprise the other agents and falsify to some extent their expectations. As a result, individual agents may change their perception of the central bank's behaviour to some extent and, consequently, they may change their own behaviour.

Given that the central bank behaves in the assumed way, the simulation - in order to be the most likely picture of the future - has to predict all these changes and their implications for the behaviour of all agents. The closer the underlying predictive model is to the ideal of a fully micro-founded, disaggregated, structural model of the economy, the better able the simulation will be to predict the changes.

In practice, it is almost impossible to build ideal, fully structural, micro-models in which the decision-making of each agent is explicitly modelled. Instead, actual predictive models are of a more or less reduced, aggregated form, and the structure of, and coefficient values in, many of their relationships are based on regularities observed in the past when all agents, including the central bank, behaved in roughly the most likely, expected way.

While unexpected behaviour on the part of the central bank would not necessitate a change in the structure and values of the fully structural models, it may imply the need to change the structure of, and/or values in, the reduced-form relationships. This is one interpretation of the Lucas (1976) critique: the assumption that the central bank behaves in an unexpected way may imply a need to change the structure of, and/or coefficient values in, the rest of the predictive model. And here lies the key problem of simulations: it is very difficult to guess exactly how the structure and/or coefficient values should change. Indeed, it is so difficult that model-builders often do not take these changes into account. The decision not to incorporate these changes, however, causes the results of the simulation to deviate from what they should be, namely the most likely picture of the future given that the central banks behaves in the assumed way. The simulation thus contains an error. We will call such an erroneous simulation "degenerated".

To take a simple example, suppose that the IS curve in a given model is articulated as the following relationship:

$$
y_{t}=b_{0}-b_{1} .\left(R_{t}-E_{t} \pi_{t+1}\right),
$$

where $y_{t}$ is the output gap, $b_{0}$ and $b_{1}$ are coefficients, $b_{1} \geq 0, R_{t}$ is the current nominal interest rate and $E_{t} \pi_{t+1}$ is expected future inflation, so that $\left(R_{t}-E_{t} \pi_{t+1}\right)$ is the current real rate of interest. In reality, the relationship between the output gap and the real interest rate may not be linear, but normally, when agents in the economy expect the central bank to act so as to achieve the inflation target, the linear approximation may imply only negligible discrepancies vis-à-vis reality. If, however, the 
bank starts to behave in a way (as possibly assumed in a simulation) which suggests that it no longer aims to fulfil the target, agents will conclude that the actual target is different. Let's say it seems much higher than the official target. In that case, $E_{t} \pi_{t+1}$ may be much higher than it would have been otherwise. This change in expectations may still be captured correctly by other equations in the model. But the agents may think that higher inflation means higher volatility of prices, higher uncertainty, etc., and the boost in their spending (due to the lower real interest rate) may be less than proportionate, causing the gap to shrink by less than it would have done if the linear relationship still held. Therefore, once we steer away from the "normal" behaviour of the central bank on which the specification of the model is based and for which it works fairly well, the picture of the future drawn by the model is incorrect unless the model is modified appropriately (in this case, $b_{1}$ needs to be lowered).

Of course, if the central bank's trajectory assumed in the simulation is not far from the bank's most likely trajectory (so that the simulation is close to a standard forecast), then the implied changes that should be made to the rest of the model may be negligible and also the error of the simulation may be negligible (see Leeper and Zha, 2002). An example would be a simulation where we want to see what would happen if a needed rate cut is postponed by the central bank by three months. Given all sorts of uncertainties in the practice of monetary policy, this delay may not surprise agents in the economy very much, so that the existing forecasting model may remain roughly valid and the simulation may be close to a forecast. Another example of a simulation which will often be close to the forecast (especially when the economy is relatively stable and the central bank's monetary policy has become relatively predictable) is a simulation where the central bank's behaviour is assumed to be identical to market participants' expectations of its behaviour as implied by the yield curve.

The less realistic is the assumed trajectory of the central bank, the more significant will be the implied changes and the larger will be the error, that is, the more degenerated will be the simulation. To return to the above example, consider a period of growing domestic demand when a rate hike is in order. In such a situation, a simple simulation with constant interest rates for the next several quarters may if the coefficient $b_{1}$ is not decreased - show a much narrower negative or much wider positive output gap than there would actually be if nominal interest rates were to stay constant. On the basis of this degenerated simulation, the central bank may increase the interest rate by more than is necessary.

To sum up, on the level of construction, the main problem with simulations is that they may be more or less degenerated and therefore provide more or less misleading information. On the other hand, by constructing simulations, we avoid one of the problems that have to be dealt with when constructing a forecast: the difficulty of identifying the most likely reaction function of the central bank. In simulations, either no reaction function of the central bank is identified and various trajectories of its future behaviour are simply assumed (like the no-change trajectory), or various reaction functions may be inserted into the predictive model without trying to earmark the most likely one. 


\subsection{Forecasts and the Specification of the Central Bank's Reaction Function}

Constructing a forecast, on the other hand, is impossible without identifying the most likely reaction function. ${ }^{3)}$ As with any economic agent's reaction function, this is not an easy task. Some authors (e.g. Vickers, 1998) think it is simply not feasible. We are not a priori so sceptical. There are several approaches that come to mind, each of them assuming that there are data and methods reliable enough to produce a reaction function specification that will be more reliable than a direct guess (however educated). One approach, which we will call the "loss function" approach, is based on determining the loss function of the Board and then transforming it through model optimisation into the "true", or most likely, reaction function. A second approach, which we will call the "shock response" approach, rests in presenting the Board's members with simulations showing model responses to different shocks under various reaction functions. Another approach, which may be called the "estimation" approach, aims at extracting the reaction function from the Board's past decisions. We will now discuss these three approaches in more detail.

In the first step of the "loss function approach", the Board's members are shown a table with a few key variables and they fill in the relative weights they assign to (the stabilisation of) the given variables in comparison with the others. If only two variables (such as inflation and output) come into question, the Board's members can indicate their preferences graphically - by picking a specific point on a curve linking various combinations of variability in these two variables. In the second step, the model-builder constructs a loss function based on the answers. The last step is to transform the loss function through model optimisation into the most likely reaction function. This approach combines a very crude questionnaire part in the first two steps with rigorous model optimisation in the last step.

Although this way of identifying the central bank's reaction function may seem attractive at first glance, the problem is that it depends heavily on the assumption that the Board's members are able (with the help of the model-builder in the second step) to formalise their preferences and are able to do so in a non-biased way. The aggregation of the responses of the individual members of the Board is no easy task either: should the model-builders weigh the responses equally or should they try to construct weights based on how strong the positions of the individual members within the Board appear to be? Another problem, voiced by Goodhart (2001), is the complexity of the optimal control approach; it may lead the Board's members "to regard the whole exercise as a mysterious 'black box"' (p. 173), limiting significantly their ability to explain to the public the forecast and their decisions based on it. Also, the optimal reaction function that comes out of this approach is often too complex to be useful as a guide for policy discussions. Sometimes, the signs of some of the variables in the reaction function may even be counter-intuitive. For examp-

\footnotetext{
3) The concept of the forecast as the most likely way things will unfold in the future implies that we do want the most likely reaction function, even if it "cannot be directly related to a reasonable optimality condition" and/or "in practical simulations on different macro models, its performance is inferior and nonrobust". In contrast Svensson (2001, p. 45) takes a more normative approach when he sees these properties of the reaction function used in the New Zealand predictive model as reasons to consider a different reaction function.
} 
le, in the model of the Czech economy presented in Hlédik (2002), the optimum reaction function has the following form, in which the coefficient on the German GDP deflator $(\alpha 13)$ comes out - counter-intuitively - negative (the general message is clear even without explaining the individual symbols' meanings):

$$
\begin{aligned}
i_{t}= & \alpha_{1} \cdot i_{t-1}+\alpha_{2} \cdot y_{t}+\alpha_{3} \cdot y_{t-1}+\alpha_{4} \cdot \pi^{\text {net }}{ }_{t-1}+\alpha_{5} \cdot \pi^{\text {net }}{ }_{t-2}+\alpha_{6} \cdot \text { defl }_{t-1}+\alpha_{7} \cdot \text { defl }_{t-2}+ \\
& +\alpha_{8} \cdot \text { deff }_{t-3}+\alpha_{9} \cdot \pi^{\text {adm }}{ }_{t}+\alpha_{10} \cdot \Delta n e r_{t}+\alpha_{11} \cdot \pi^{i m p}{ }_{t}+\alpha_{12} \cdot \pi^{i m p}{ }_{t-1}+\alpha_{13} \cdot \text { defl }^{\text {Ger }}{ }_{t}+ \\
& +\alpha_{14} \cdot i^{\text {Ger }}{ }_{t}+\alpha_{15} \cdot \text { risk }_{t}+\alpha_{16} \cdot y^{G e r}{ }_{t}+\alpha_{17} \cdot \text { rer }_{t-1}+\alpha_{18} \cdot r_{t-1}
\end{aligned}
$$

The "shock response" approach is similar to the loss function approach, but it combines, in a sense, all the three steps into one. To begin with, the model-builder designs a few realistic reaction functions, runs the model with these reaction functions under various shocks (demand, supply, risk premium and other shocks) and then presents the Board members with the responses of the key variables to the shocks under the various reaction functions. ${ }^{4)}$

If the Board members feel happy with the response paths of the variables under one of the suggested reaction functions, that reaction function is chosen as the most likely one. If they are not satisfied, the assumed reaction functions are changed and the responses to the same shocks under the new reaction functions are presented to the Board and assessed. This iterative process may go on until the Board accepts the reactions, which means that the most likely reaction function has been found. Unfortunately, this is a rather demanding and time-consuming process. Moreover, since the individual iterations are simulations, they are subject to the "degeneration" problem described above, unless the model-builder, having changed the central bank's reaction function, is able to adjust the rest of the model so that it captures the changes in the behaviour of the other agents corresponding to the change in the central bank's reaction function.

The "estimation approach" builds on past data on monetary policy decisions and other variables. If we believe the central bank responds in a forward-looking manner to fluctuations in future inflation and future real economic activity, it may occur natural at first sight to try to estimate the relationship between the central bank's interest rate at a particular moment in time and later actual figures on inflation, real economic activity, etc. But in practice, interest rates react in a forward-looking manner to shocks that would otherwise push inflation away from the target. This means that, if policy is successful, past data will show that interest rates have fluctuated while inflation has stayed more or less at the target level..5) To sum up: if policy reacts to anticipated shocks successfully, their later impact on prices will be unobservable from actual data and the estimation of the central bank's reaction function from past data is impossible.

4) Goodhart (2001) and Svensson (2001) consider an exercise of this nature, but they view it as a way for the Board to find an appropriate response to actual individual shocks, i.e. they suggest doing this for each coming shock anew rather than doing it once for various hypothetical shocks as a way to determine the reaction function to be used for constructing forecasts for some time into the future.

5) In this paper, when talking of fulfilling the central bank's inflation target, we implicitly mean a balanced fulfilment of the inflation target and any other targets the central bank may have (minimising the output gap, etc.). 
A more promising alternative is to realise that the Board's decisions are based on forecasts, not actual future data, and that the forecasts are always based on past and actual data. Reacting to forecasts then basically means reacting to a combination of past and actual data. One may therefore try to obtain the reaction function by constructing and estimating a VAR-type relationship between interest rates and several other variables, such as inflation, the domestic and foreign output gap, the exchange rate, etc. Some central banks may even have a long time series of simulations of future development (usually based on the constant interest rate assumption) at their disposal. In that case, acknowledging that it is based on a simplistic picture of monetary policy decision-making in the inflation targeting regime, we can directly estimate the relationship between the divergence of the simulated path of inflation from the target as an independent variable and (lagged) interest rates as a dependent variable.

The difficulties central banks have when trying to come up with the most likely reaction function may seem paradoxical, given that it is their own reaction function. In fact, however, the central bank's model-builders face similar difficulties when modelling the behaviour of the other agents in the economy. The model behaviour of the central bank is special only in the sense that the central bank has a choice: either to ask its model-builders to treat the bank in the model in the same way as they treat other agents, that is, to model the bank's most likely reaction function (arriving at a forecast) or to ask the model-builders to construct simulations instead of a forecast. If the first option is chosen, then one (or preferably a combination) of the above-mentioned or other approaches must be attempted, bearing in mind the limitations.

Even though forecasts and simulations seem conceptually quite different ways of assessing the future, some central banks in fact take a middle path. Aware of the problems related to simulations (degeneration and possible model explosion due to the absence of stabilising reactions of the central bank $\mathrm{k}^{6}$ ), they combine a simulation and a forecast. More specifically, such a hybrid assessment of future inflation assumes that the central bank's interest rate is constant for the first $s$ quarters and that from quarter $s+1$ onwards the central bank "wakes up" and tries to bring future inflation back to target with a given reaction function. Of course, the reaction function should be the most likely for this case and thus it may differ from the reaction function that would be the most likely for the case where the bank is reacting all the time. The value of $s$ is usually selected to represent the end of what the central bank considers the horizon of most effective monetary policy transmission. Therefore, it may seem that up to and including quarter $s$, we get a standard constant interest rate simulation that is afterwards saved from possible explosion by "switching on" the central bank's reaction function. In fact, however, forward-looking agents in the forecast (if there are any) anticipate the switching-on of the reaction function. The anticipation may influence their behaviour already in the simula-

6) Model explosion may in fact be viewed as an example of degeneration: the simulation gives results that are very unlikely in reality and it does so because it is built on the wrong implicit assumption that even though the central bank is now (in the simulation) reacting in unexpected ways, the economy will work along the same lines it worked previously, when the central bank behaved roughly as expected. 
tory phase, in which case the simulation ceases to be a standard constant interest rate simulation. At times, this departure from the standard form of a constant interest rate simulation may have an influence on the forecasted paths of inflation and/ or other variables, and that is why it should be noted in both monetary policy decision-making and communication.

\section{Use of Simulations and Forecasts in Monetary Policy Decision-Making}

As in the previous section, we will start with simulations and we will assume unless noted otherwise - that they are constructed without any degeneration. The reason for the attractiveness of simulations in the area of decision-making is clear - they enable the central bank to do what Lucas (1976) calls "policy evaluation". That is, they show what the results would be (in terms of inflation, output, etc.), if the central bank follows alternative future interest rate trajectories. Specifically in inflation targeting, once we compare the simulated future development of inflation with the inflation target, we may get an idea about the direction in which the central bank's interest rate trajectory assumed in the simulation needs to be adjusted in order to bring inflation closer to the target at the policy horizon.

Unfortunately, the policy advice a simulation gives is incomplete: it is qualitative (direction) but not quantitative (extent). The information about how much to adjust the trajectory has to be obtained elsewhere. For example, we can analyse the monetary policy transmission mechanism in order to get an idea of the sensitivity of inflation in various future horizons to a unitary change in the central bank's current interest rate. Another way of supplying quantitative advice is to construct and present to the Board's members a fan of simulations showing the future development of the economy assuming several alternative trajectories of the central bank's interest rate. The Board's members then simply select the simulation whose results they like the most, ask for the values of the interest rate trajectory upon which the selected simulation is based and set the actual interest rate in accordance with the starting value of that trajectory. The process can even be iterative - the Board selects a simulation from a fan of simulations, the staff prepare and present a fan composed of a few variations on the selected simulation, the Board selects again, etc. Note a link to the construction of a forecast: after a sufficiently high number of iterations, the simulation selected at the end should be very close to a forecast. Understandably, the problem with the "fan approach" is that it is a rather time-consuming process.

Contrary to Martijn and Samiei (1999), we think that using a simulation as a basis for decision-making is compatible with the empirically observed interest rate smoothing. For example, if the simulation and additional quantitative analysis suggest that the interest rate should be increased by 1 percentage point to bring future inflation back to the target, the bank's Board may decide to realise this increase in several steps. It is true, however, that in the meantime the simulation will indicate a missing of the target, suggesting that each of the decisions in the series was "incorrect". It is up to the bank to explain in its communication with the public the concept of interest rate smoothing, or, in other words, to explain that the decisions have to be judged as a series rather than each one separately. 
The last issue we want to discuss in connection with the use of simulations in monetary policy decision-making is the assumption of an unchanged central bank interest rate. Theoretically, simulations can assume various trajectories of the central bank's interest rate, from completely flat trajectories (an unchanged central bank's interest rate) to very complex shapes. In practice, however, central banks tend to prefer the flat extreme, that is, trajectories which assume no change in the interest rate.

Board's members at these central banks apparently see advantages in the constant central bank's interest rate assumption over other, more complex assumptions. Maybe they think that such a simulation is easiest to grasp and work with, because a constant nominal interest rate keeps the impact of monetary policy on the economy constant (which is not true if inflation expectations change and if it is the real interest rate that matters). Or maybe the Board's members think that such an assumption is just a naturally obvious choice for a simulation. Or they perceive the extreme simplicity of the trajectory as showing most blatantly to the public that it is a mere simulation, not an actual forecast of the central bank's future interest rate trajectory. Another reason, stressed by Kohn (2001) and Goodhart (2001), is that given the often very heated debates on what the current monetary policy stance should be, the Board's members may hardly ever be able to arrive at any more "reasonable" future path of the central bank's interest rate than the constant one. Goodhart also notes that the constant interest rate simulation induces the Board to take a preemptive decision now, whereas giving thought to simulations assuming other trajectories may lead the Board's members always to prefer trajectories in which any action occurs at a later time (when more information will be available to judge the appropriateness of the action).

On the other hand, the constant interest rate assumption has some serious disadvantages. One is implied by the finding of Sargent and Wallace (1975) that constant interest rates may imply a non-unique price level in the long run. Another disadvantage, alluded to already in Section 2, has been assumed away in this section so far. The more unrealistic (vis-à-vis current and anticipated economic circumstances) is the no-change trajectory that staff are required to assume in the simulations, the higher is the risk of degeneration of the simulation. Less degeneration might be achieved by taking more complex and more realistic trajectories.

Quite apart from the danger of degeneration, we have to be aware of the fact that in the near future, the Board's decision-making will be focused on a later segment of the target and the Board may decide then to change interest rates, thereby violating the constant interest rate assumption made today for the purposes of today's decision-making. Therefore, if simulations assume for the interest rate a constant rather than a more realistic path beyond the current period, and if the target horizon is longer than the shortest lag at which the interest rate affects inflation (the inflation control lag), the simulations have a time inconsistency element built into them (Leitemo, 2003).

Let's now briefly discuss monetary policy decision-making based on forecasts. An integral part of the forecast is the trajectory of the central bank's future interest rates. The Board is thus presented with an interest rate trajectory that is consistent both with the assessment of the future and with fulfilling the inflation target in accordance with the reaction function specified in the forecasting model. This trajec- 
tory can then be viewed as a policy suggestion. It could also be arrived at through a series of simulations, but the construction of a forecast seems to be the more straightforward way. The high "fixed costs" connected with arriving at the most likely reaction function are offset by very low "variable costs", which in the case of simulations may be quite high (see Section 2).

On the one hand, the suggestion regarding the trajectory of interest rates may be viewed as an advantage. It can be compared to what the Board's members a priori thought an appropriate trajectory might look like, and if there are significant differences, they may be discussed in order to identify their sources and perhaps to modify the various assumptions underlying the forecast (Hampton, 2002). On the other hand, the Board's members may feel obliged to accept the suggested trajectory of the central bank's interest rate - they may feel "locked up in it". In reality, however, they do not have to agree with the suggestion. For instance, they may attach various additional risks to the basic forecast being presented. If the forecast is then published as "the Bank's forecast" rather than "the staff of the Bank's forecast", however, the Board's members' disagreement with the forecast may be a problem. This brings us to communication issues, which are discussed in the next section.

\section{Use of Simulations and Forecasts in the Central Bank's Communi- cation}

Today, many central banks strive for a high degree of transparency. Many central bankers would also agree that publishing an assessment of future inflation is a key characteristics of transparency. Nevertheless, the specific reasons for publishing such an assessment (apart from the fact that other central banks publish them too) may not always be entirely clear.

\subsection{Reasons for Publishing an Assessment of Future Inflation}

Since the form in which the assessment of future inflation is published must reflect the reasons the bank has for publishing it, let us start by discussing these reasons. We see two basic reasons. The first is that it can anchor expectations at times when the central bank expects to temporarily miss its inflation target, so that the target in itself ceases to serve as the usual expectation anchor. There are situations (mainly supply shocks) where it may be economically legitimate and justified for the central bank not to react (or to react only partially) to an expectation that its inflation target will be missed. These situations arise more frequently in small open economies, which are more exposed to external shocks. ${ }^{7)}$ In such situations the public may ask what they should expect, given that inflation will diverge from the target; the central bank can answer by publishing the anticipated future course of inflation (assuming that it does show a return into the target corridor). In the other case, i.e. when the assessment of future inflation signals that the inflation target will be fulfilled, the publication of the assessment will not bring much added value in terms of anchoring expectations, but it will not do any harm in this area either.

7) These central banks sometimes even explicitly state that their inflation target may not be fulfilled under specific types of shocks. This arrangement is then referred to as "escape clauses". 
Obviously, the only type of assessment of future inflation suitable for this purpose is the currently valid forecast. By "currently valid" we mean a forecast which also incorporates the Board's latest decision. This implies that if the Board makes its decision on the basis of a forecast, but the decision is not as forecasted, then a new forecast has to be constructed to incorporate the actual decision (which may take some time). A simulation - or even a forecast that does not incorporate the Board's last decision - is not a suitable expectation anchor, as it is not the central bank's best guess about the future.

The other reason for the central bank to publish its view on future inflation is that the view can serve as an explanation of the decision that the Board has just taken. This explanation can have two forms, either negative or positive. The negative form of explanation shows what unwelcome results would probably have ensued if the decision had not been taken. A simulation or a forecast not including the decision being explained will serve well this purpose. However, only the appropriate direction, not the appropriate extent, of the decision to be taken is shown. This form thus allows only a qualitative assessment of the appropriateness of the decision actually taken. A central bank that publishes a simulation also runs the risk that the simulation will be incorrectly understood by the public to be a forecast (Martijn and Samiei, 1999, Bofinger, 2000), which - in some situations - may have rather detrimental consequences. For example, the experience of the Czech National Bank when it was publishing simulations showed that the media did have a tendency to present constant interest rate simulations produced by the central bank and forecasts produced by other institutions side by side and to compare them, when in fact they were conceptually incomparable. The risk of taking a simulation as the forecast may increase (but the implications may be relatively low) if the simulation is built on the assumption that the central bank behaviour will coincide with market participants' expectations.

The positive form of explanation shows what welcome results will probably ensue thanks to the decision having been taken. This form of explanation is informationally richer, as it shows that the decision actually taken was the appropriate one both qualitatively and quantitatively, that is, in terms of both direction and extent. For this form, only the currently valid forecast can be used.

\subsection{Publishing the Trajectory of the Interest Rate and Other Variables Consistent with the Forecast}

The above analysis of the motivation for communicating the central bank's view of the future seems to imply that overall, a forecast may be preferable to a simulation. Several arguments can, however, be raised against publishing a forecast. We will mention two of these, calling them the "commitment argument" and the "destabilisation argument".

The "commitment argument" (Goodhart, 2001, Mishkin, 2004) runs as follows. If the inflation forecast is to be credible, the agents need to know its key properties and assumptions. If the central bank is an important player in the economy, then the path of the central bank's interest rate is an important component of the forecast and it should be made public. The problem is that agents in the economy may view the interest rate trajectory as a commitment of the central bank to follow it in its future 
monetary policy decisions. Of course, there are reasons why the trajectory should not be viewed in this way. First, the Board's members may have other decision inputs beside the forecast, they may - as mentioned in Section 3 - attach various additional risks to the forecast, and so on. ${ }^{8)}$

Moreover, the trajectory, just as the whole forecast, is based on today's information, so that any new piece of information obtained later may potentially modify the forecast and thus the future part of the central bank's interest rate trajectory. These reasons may seem difficult to communicate to the general public and therefore the perception of commitment may seem hard to eradicate. Nevertheless, the only existing long-term experience, that of the Reserve Bank of New Zealand, which has been using and publishing forecasts since 1997, does not support the commitment argument: "Our observers - namely the public and financial markets - also accept the conditionality of the projections and do not see them as being a constraint on OCR (Official Cash Rate) settings" (Hampton, 2002, p. 8; see also Archer, 2005, McCaw \& Ranchhod, 2002). Even if the bank succeeds in explaining that it is not, and cannot be, obliged to follow the published trajectory, some authors (e.g. Bofinger, 2000) fear that frequent changes to this forecasted trajectory due to newly arriving data may undermine the reputation of the central bank.

The second argument against publishing a forecast, the "destabilisation argument", is more economic in nature. The argument is that if the central bank is perceived to produce high quality forecasts and if it publishes a forecasted trajectory of certain financial variables, namely short-term market interest rates and the exchange rate, this may have a highly destabilising effect on the respective markets. More specifically, if the central bank publishes a forecast showing an exchange rate appreciation, this forecast may concentrate market expectations at the forecasted level of appreciation as well as decrease future uncertainty. This concentration of expectations and reduction in uncertainty may then cause the appreciation to occur much faster. An easy pragmatic solution to this problem is to publish the forecasted trajectory of the exchange rate with some fuzziness added, e.g. by publishing the forecasted trajectory of the effective exchange rate.

While we think that the destabilisation argument may be true for the exchange rate, we believe the same argument does not hold in the case of short-term market interest rates. The reason is that the central bank is usually able to control current short-term market interest rates at the forecasted level and the market is aware of this ability of the central bank. This has a useful implication: the published forecast of the central bank's interest rate trajectory may help concentrate market expectations of future short-term market interest rates at the level suggested by the central bank's forecast, thus concentrating, through the term structure, today's longterm interest rates at a level consistent with the forecast.9)

8) In other words, publishing a forecast with the interest rate trajectory does not necessarily mean a "policy bias" in the sense of, for example, the Fed's "bias announcements" published between May 1999 and January 2000.

9) Another argument against being too outspoken in the communication of the forecast, an argument related to efficient use of information by the market, is discussed in Amato, Morris \& Shin (2002), Svensson (2006) and Morris, Shin \& Tong (2006). 
To conclude this section, there are arguments both for and against publishing the interest rate trajectory consistent with the given forecast. Fortunately, a compromise solution similar to the exchange rate case may be found. Namely, the central bank may choose how explicit it is in communicating the future interest rate trajectory. The Reserve Bank of New Zealand, for instance, publishes both a chart and a table of future quarterly averages of the 90-day interest rate. As an example of a less explicit publication, the Czech National Bank describes in simple words the direction in which interest rates consistent with the presented forecast will move in the future. ${ }^{10)}$ On the other hand, there are several inflation targeting central banks which do not publish any information about their forecast of interest rates, although they do produce it internally (e.g., Chile, Canada, Colombia, Peru, Slovakia).

\section{Conclusion}

Given its focus on difficult operational dilemmas, this paper can hardly have a clearcut conclusion in the form of specific recommendations for inflation-targeting central banks in general. As we saw, the choice between simulations and forecasts has several dimensions, in each of which various arguments can be raised on both sides. Before opting for one of the two approaches or switching between them, specific circumstances at the given central bank have to be considered - the sophistication of the modelling apparatus available, the length and quality of the data series that can be used, the degree of risk of the public misunderstanding the communicated message, etc. Of course, the ultimate choice will to a large extent depend on which of the two options seems more "user-friendly" to the Board's members.

\section{References}

Amato, J.D., Morris, S., Shin, H.S. (2002), „Communication and Monetary Policy.“ Oxford Review of Economic Policy, 18, pp. 495-503.

Archer, D. (2005), "Central Bank Communication and the Publication of Interest Rate Projections." Paper for Sveriges Riksbank Conference on Inflation Targeting, Stockholm, June 2005. http:// www.riksbank.com.

Bofinger, P. (2000), "Inflation Targeting: Much Ado about Nothing (new)," mimeo. http:// www.wifak.uni-wuerzburg.de/vwl1/downloads/inta2000.pdf.

Goodhart, C.A.E. (2001), "Monetary Transmission Lags and the Formulation of the Policy Decision on Interest Rates." FRB of St. Louis Review, July/August, pp. 165-186.

Hampton, T. (2002), "The Role of the Reserve Bank's Macro-Model in the Formation of Interest Rate Projections." Reserve Bank of New Zealand Bulletin, 65(2), pp. 5-11.

Hlédik, T. (2002), "Optimum Monetary Rules in a Dynamic Model of the Czech Economy." Finance a úvěr, 52(3), pp. 164-185 (in Czech).

10) This may reflect the fact that in the case of the RBNZ, there is a single decision-maker, the governor of the RBNZ, whose (most likely) reaction function is mapped into the forecast, whereas in the case of the $\mathrm{CNB}$, there are seven decision-makers whose "average" reaction function enters the forecast. 
Kohn, D.L. (2001), "Report to the Non-Executive Directors of the Court of the Bank of England on Monetary Policy Processes and the Work of Monetary Analysis." Bank of England Quarterly Bulletin, 41(1).

Leeper, E.M., Zha, T. (2002), "Modest Policy Interventions," NBER Working Paper No. 9192.

Leitemo, K. (2003), "Targeting Inflation by Constant Interest Rate Forecasts." Journal of Money, Credit, and Banking, 35(4), pp. 609-26.

Lucas, R.E. (1976), "Econometric Policy Evaluation: A Critique," in Brunner, K., Meltzer, A.H. (eds), The Phillips Curve and the Labor Markets, supplementary series to Journal of Monetary Economics, pp. 19-46.

Martijn, J.K., Samiei, H. (1999), "Central Bank Independence and the Conduct of Monetary Policy in the United Kingdom," IMF, WP/99/170.

McCaw, S., Ranchhod, S. (2002), "The Reserve Bank's Forecasting Performance." Reserve Bank Bulletin, 65(4), pp. 5-23.

Mishkin, F. (2004), "Can Central Bank Transparency Go Too Far?" in Kent, C., Guttmann, S. (eds.), The Future of Inflation Targeting, Sydney, Reserve Bank of Australia.

Morris, S., Shin, H.S., Tong, H. (2006), "Social Value of Public Information: Morris and Shin (2002) Is Actually Pro-Transparency, Not Con: Reply." American Economic Review, 96, pp. 453-455.

Sargent, T.J., Wallace, N. (1975), "Rational' Expectations, the Optimal Monetary Policy Instrument, and the Optimal Money Supply Rule." Journal of Political Economy, 83(2), pp. 241-254.

Skořepa, M., Kotlán, V. (2003), "Inflation Targeting: To Forecast or to Simulate?" Internal Research Policy Note, Czech National Bank, No. 1/2003.

Svensson, L.E.O. (1997), "Inflation Forecast Targeting: Implementing and Monitoring Inflation Targets." European Economic Review, 41, pp. 1111-1146.

Svensson, L.E.O. (2001), "Independent Review of the Operation of Monetary Policy in New Zealand: Report to the Minister of Finance." http://www.rbnz.govt.nz/monpol/review.

Svensson, L. (2006), "Social Value of Public Information: Comment: Morris and Shin (2002) Is Actually Pro-Transparency, Not Con." American Economic Review, 96, pp. 448-452.

Vickers, J. (1998), "Inflation Targeting in Practice: The UK Experience." Bank of England Quarterly Bulletin, 38, November, pp. 368-375. 